\title{
POWER PLANT COOPERATION IN DISTRICT HEATING CONSIDERING OPEN ELECTRICITY MARKET
}

\author{
R. Oleksijs*, A. Sauhats, B. Olekshii \\ Riga Technical University, Power Engineering Institute, \\ 12-1 Azenes Str., Riga, LV-1010, LATVIA \\ *e-mail: romans.oleksijs@edu.rtu.Iv
}

The paper analyses the possibilities to form a coalition of several heat energy providers in order to participate in the district heating market considering the open electricity market. Cooperation would allow the participants to better dispatch the existing energy sources and would ensure higher total profit for the participants. The objective function for such a cooperation is provided. To optimise the operation of the coalition, mixed integer linear programming is used, considering constraints of different heating energy market participants and the need to fulfil heating energy balance. If any additional profit is made, it is shared between coalition participants according to the Shapley value, which grants interest for market participants to form the coalition. Case study based on historical hourly data is provided and numerical results are presented in the paper.

Keywords: biomass CHP, CCGT, district heating, district heating market, HOB, market participant coalition, wood chip CHP.

\section{INTRODUCTION}

According to statistics, $26 \%$ of all energy in the European Union (EU) is used for space heating and $5 \%$ is used for hot water production, which results in total energy consumption of 3985 TWh. $45 \%$ of this energy is produced using natural gas and $12 \%$ - using biomass [1]. Study held in [2] showed that an increase in heat demand would make the district heating market more efficient, i.e., combined heat and power (CHP) plants operating in city district heating zones would need to compete both in electricity and in district heating markets.

Worldwide, heat demand is mainly satisfied by burning wood or fossil fuels, 
which lead to local pollution and global greenhouse gas emission [3]. District heating systems have been used since the 14th century. In Northern European countries such as Sweden and the Baltic States, district heating is widely used, supplying more than $50 \%$ of total heating energy. Development of district heating systems is reported in various countries. In [4], authors forecast growth of CHP by 2030. Different energy sources could be used for district heating, such as fossil fuels, nuclear power, waste heat, solar power, ground-source heat pumps and biomass [5], [6].

In the past, energy conversion was seen as a direct conversion of energy to electricity and such by-product as heat was usually treated as waste. Efficiency of district heating has increased due to fuel use because it provides a possibility to use a co-generation process, in which both electricity and heating energy are generated and give higher fuel efficiency than single electricity generation. Combined generation also has lower impact on the environment. Combined heat and power plant is a step towards system improvement since previously wasted heat is recovered and used as a valuable product [2], [7], [8].

In the Nordic countries, district heating is common for municipalities; usually heat energy is provided by CHP plants combined with heat only boilers, which are used to cover peak loads. CHPs not only cover heat demand of the city, but also sell electricity in the electricity market [9], [10].

Renewable energy sources are widely used in Europe to reach environmental objectives. Electricity generation from renewable sources is usually fluctuating, which forces classic CHPs operate in a more cyclic mode due to changes in the electricity price in a wide range during the day. Various technologies and solutions are used to increase flexibility of CHP especially in case of highly efficient CCGT power plants [4], [10].

Biomass has become a very promising fuel for electricity generation due to its $\mathrm{CO}_{2}$ emission reduction potential and its suitability for use in CHP. The European Union continuously aims at reducing greenhouse gas emissions and using more renewable power. The use of biofuel grows in Europe every year [11]. In opposite to wind and solar generation, biomass can be used to provide base load or controllable load. In this context, various technologies such as steam or gas turbines, steam engines, organic Rankine cycle (ORC) or Stirling engines can be used. These technologies mainly differ in their heat supply, whether they require an internal (e.g., gas turbine and engine) or external heating (e.g., ORC, steam and Stirling engines) [12].

Thermodynamic processes requiring internal heating are limited to the application of liquid or gaseous fuels. For solid biomass gasification technologies could be used to make them applicable to internal burning technologies. External fired thermodynamic cycles can be used by the direct combustion of solid fuels and heat decoupling out of the hot flue gas. Thus, external burning technologies have lower electrical efficiency [13].

Modern energy systems are complex and consist of several interacting markets; thus, they are usually considered as individual sub-systems: electricity supply, heating supply, natural gas or hydrogen supply. However, there are a lot of benefits when the energy system is considered an integrated whole. Such benefits are the supply of energy from alternative sources, which grants higher system security; energy efficiency could be raised; energy losses, costs and emission could be minimised because of synergy between various energy vectors; energy flows can be controlled [8], [14]. 
Good example of an integrated energy system is a district heating system where CHP, heat only boilers, electrical boilers and heat pumps are operating. Such integrated systems can operate more efficiently and be more flexible, which is important due to renewable electricity generation penetration [14].

CHP is a key technology to link electrical and heating power sectors for its high generation efficiency and high distribution in the Northern countries. Integration of renewable energy sources forces CHPs to become more flexible in the electricity market. It becomes even more challenging to operate CHPs as they should participate in electricity and heating energy markets, which are ruled by different operators [15].

In recent years, the concept of energy hub has become very popular, because it considers several energy flows, such as fuel, electricity and heating energy. This approach allows for a simple analysis of couplings and interaction between different infrastructures. Similar to the standard economic dispatch approach for electricity generators, a general optimality condition can be derived for optimal dispatch of multiple energy carriers. Potential application of such an approach includes planning of integrated systems, multi-carrier generation scheduling and security analysis of coupled systems. This approach has great potential for co-generation and trigeneration optimisation [7], [16].

Nowadays it is important to ensure a high comfort level and energy efficiency, which can be reached by adopting different control and management systems. Authors of [17] analyse the district energy system in terms of electricity flow optimization to ensure a comfort level in building and better planning of day-ahead electricity markets to negotiate balancing expenses. Thus, for places with the district heating network such an approach should be modified.

As electricity prices change hour to hour, to gain most income CHP should produce maximum electricity power during hours with high electricity price and avoid operation during hours with low electricity price. However, heat demand should be fulfilled all the time. The study [9] analyses heat storage performance to ensure optimal operation of CHP and to reduce operating hours of heat only boilers.

In [18], authors seek for optimal sources of energy for the city, considering such technologies as remote nuclear power plant, biomass CHPs, natural gas CHPs and ground \& air heat pumps. To find an optimal solution, linear programming was used. Thus, an attempt was made to analyse specific needs of one city, without considering the electricity or heat energy market.

Authors of [19] concern about optimal dispatch of large coal fired units, which, according to [1], represent only $9 \%$ of total energy produced for heating. Thus, in some countries this percentage is much higher. Optimization covered operation of CHPs within the electricity market, and the main objectives were to maximise income from electricity sales and minimise production costs of heat energy.

Authors in [20] aim at minimising total costs of the integrated power system considering such sources of electricity as photovoltaic panels, wind turbines, electric boilers, CHP and battery electricity storage systems. Natural gas fired CHPs were considered as a heat energy source. The objective was to minimise daily net operation costs, without any market consideration.

Detailed optimization considering network constraints is provided in [21]. In the study, CHP and non-CHP units were used as a heat and electricity source. The objective was to reduce total production costs.

Authors in [22] developed a model of 
the district heating and electricity system considering gas fired CHPs, biomass and gas fired heat only boilers (HOB). The objective was to prove that moving from rule-based production to optimizationbased predictive control could result in significant savings.

In [8], authors propose considering natural gas supply in the optimization model as well as electricity and heat energy production of CHP. The proposed approach demonstrated a possibility to optimize power and gas flows.

In [23], authors suggest to consider not only operation optimization of heating energy units of a certain company, but also to evaluate cooperation with other producers. The main aim was to increase income and do not sacrifice interests of society. Results of [23] demonstrated possibilities to gain higher overall profit when wood chip and gas fired CHP operate in coalition. The study also demonstrated how the Shapley value could be applied to fairly split additional income of coalition members. Unfortunately, only average heat production costs for generation units were considered, costs of fuel were taken as fixed costs, which did not represent market relations. Interaction with electricity market was unclear.

In Europe, common types of CHP are natural gas fired or coal fired power plants. Coal fired units usually reach electrical efficiency of 24-28\%, with overall efficiency of around $80 \%$. Due to environmental aspects, coal fired power plants are shutting down and are not under the scope. Gas fired power plants tend to use a combined cycle gas turbine (CCGT) technology to reach electrical efficiency of $42-47 \%$ and overall efficiency of $80 \%$ [24].

The most popular type of biofuel CHP is an organic Rankine cycle power plant, which can combust wood chip. Analysis of different power plants in the range of
3.7-7.4 MW showed electrical efficiency of 6-13\%, where lower efficiency was reported for smaller CHPs. Total thermal efficiency was in the range of 48-72\%, where the highest efficiency was also reported for bigger CHPs [25]. In [26], electrical efficiency of $16-36 \%$ for the newest ORC power plants is reported, gaining overall efficiency of $85 \%$.

Results of the reviewed works indicate the need to look at the energy system as a united whole. Optimization of operation considering all markets in which a power plant should participate has numerous advantages. Combined heat and power plants are very suitable for optimization considering electricity and heating energy markets. Different technologies, which are used for CHP, can give additional optimization possibilities.

In the same district heating area, power plants with different technologies can supply heating energy and electricity. Electrical efficiency of ORC power plants is lower than that of CCGT units; therefore, thermal and overall efficiency is better. It means that CCGTs have advantage on the electricity market, but biofuel CHPs - on the heating energy market. As both these technologies allow competing on electricity and heating energy markets, this leads to possible interaction of both biofuel fired and gas fired units to coordinate efforts and optimize operation in order to maximise revenue from participation in the district heating market, considering operation within the open electricity market.

This study aims at optimising different electricity and heat source operation using mixed integer linear programing (MILP). If such optimization leads to additional profit, then profit will be distributed between coopering parties using the Shapley method. Such an approach can result in more efficient use of resources leading to lower costs 
for the end-user. This study is the first step of the approach; it should indicate whether making coalition in the district heating market could make additional profit for acting parties.

Additional profit due to optimized dis- patch could be used in different ways. Usually, market rules ban any type of coalition, but if a regulator can develop clear rules of coalition operation, additional profit could be used to decrease end-user costs of heat energy.

\section{METHODOLOGY}

Three energy sources are under consideration in the present study: (1) CCGT power plant, which produces both electricity and heat energy, can also operate in a fully condensing mode (electricity production does not depend on heat energy production); (2) wood chip fired CHP, which produces both electricity and heat energy, can operate only in a full cogeneration mode (electricity production fully depends on heat energy production), and (3) gas fired HOB, which produces only heat energy.

Electricity market prices are taken from local electricity market prices of day-ahead spot market, but heat energy prices are calculated according to heat demand and electricity price. It is assumed that operation costs of the mentioned energy sources are limited by fuel costs and efficiency of each technology. Heat energy price is calculated for each energy source considering market electricity price and no additional revenue from heat energy trading. In general, heat energy price for CCGT and CHP is calculated as shown in Eq. (1), but for HOB as shown in Eq. (2). Both these equations consider minimum and maximum electrical and heat power during each hour $t$ of the period $p$.

Authors in [27] and [28] have concluded that the projected day-ahead heat energy demand might change during the day under different circumstances. This change of demand might lead to additional profit or losses due to the previously set price for heat energy. The re-dispatch during the day, for which electricity and heat prices are already set, might lead to better total profit which later might be shared among market participants granting better economic effect.

$C_{\text {th.p }}=\frac{P_{\text {el.p }}\left(\frac{C_{\text {fuel.p }}}{\eta_{e l}}-C_{\text {el.p }}\right)}{P_{\text {th.p }}}$,

where

$C_{\text {th.p }}$ - heating energy price for period $p$, EUR/MWh; $P_{\text {el.p }}$ - electrical energy produced by a power plant in period $p, \mathrm{MWh}$; $C_{\text {fuel. }}$ - fuel average market price for period $p, \mathrm{EUR} / \mathrm{MWh} ; C_{e l . p}-$ electricity average market price for period $p, \mathrm{EUR} / \mathrm{MWh}$, $\eta_{e l}$ - technology electrical efficiency; $P_{\text {th.p }}$ thermal energy produced by technology in period $p, \mathrm{MWh}$.

$C_{\text {th.HOB.p }}=\frac{\frac{C_{\text {fuel. }}}{\eta_{\text {HOB }}}}{P_{\text {th.HOB, } p}}$,

where

$C_{\text {th.HOB.p }}$ - heating energy price for $\mathrm{HOB}$ in period $p, \mathrm{EUR} / \mathrm{MWh} ; \eta_{H O B}-\mathrm{HOB}$ efficiency; $P_{\text {th. HOB. }}-$ thermal energy produced by $\mathrm{HOB}$ in period $p$, MWh.

For pre-calculation purposes, two heating energy market models were chosen: day-ahead market and week-ahead market. To calculate day-ahead or week-ahead heat prices, it is suggested that every market 
participant makes its bid at which price it can cover heating energy demand for day or week ahead. The source, which has the lowest heating energy price, produces all demanded heat during a particular hour, if it is not possible, the next cheapest source is started and then third to always cover the whole demand of heat energy at the set day- or week-ahead heating energy market price. Minimal and maximal electrical and thermal power constraints of each energy source are also considered; it is especially essential for CCGT, where heating energy production could be 0 , but minimal electrical power is limited, which leads to higher heating energy prices in some cases. It is considered that a provider of the cheapest heating energy for the day or week ahead can adapt their heating energy prices to beat rivals and gain profit. According to the previously mentioned assumption, i.e., all participants set the heating energy price considering no profit, it appears that the second and third cheapest sources will have loss in revenue if they need to operate. The provided objective function assumes very high flexibility of energy sources.

Total profit (E) of the mentioned energy source operation and participation in both markets could be calculated as follows:

$$
\begin{aligned}
& E=\sum_{t=1}^{T}\left(P_{\text {el.gas.t }}\left(C_{\text {el.t }}-\frac{C_{\text {g.t }}}{\eta_{\text {el.gas }}}\right)+P_{\text {th.gas.t }} C_{\text {th.t }}+P_{\text {th.HOB.t }}\left(C_{\text {th.t }}-\frac{C_{g . t}}{\eta_{H O B}}\right)+\right. \\
& \left.P_{\text {el.bio.t }}\left(C_{\text {el.t }}+\frac{C_{\text {th.t }} \eta_{\text {th.bio }}}{\eta_{\text {el.bio }}}-\frac{C_{\text {bio.t }}}{\eta_{\text {el.bio }}}\right)\right),
\end{aligned}
$$

where

$T$ - the calculation period in hours (day or week), h; $P_{\text {el.gas.t }}$ - electrical energy produced by CCGT at hour $t, \mathrm{MWh} ; C_{\text {el. }}$ - electricity market price at hour $t, \mathrm{EUR} / \mathrm{MWh} ; C_{\text {g.t }}$ - natural gas market price at hour $t$, EUR/MWh; $\eta_{\text {el.gas }}-$ CCGT electrical efficiency; $P_{\text {th. gas.t }}$ - thermal energy produced by CCGT at hour $t, \mathrm{MWh} ; \mathrm{C}_{\text {th.t }}$ - heat energy price at hour $t, \mathrm{EUR} / \mathrm{MWh}$; $P_{\text {th.HOB.t }}-$ thermal energy produced by gas fired heat only boiler at hour $t, \mathrm{MWh} ; \eta_{\text {HOB }}-\mathrm{HOB}$ efficiency; $P_{\text {el.bio.t }}$ - electrical energy produced by wood chip CHP at hour $t, \mathrm{MWh} ; \eta_{\text {el.bio }}-$ electrical efficiency of wood chip CHP; $\eta_{t h . b i o}$-thermal efficiency of wood chip CHP; $C_{\text {bio.t }}-$ wood chip market price at hour $t$, EUR/MWh.

Equation (3) can be divided into three parts, CCGT, HOB and biofuel CHP, in accordance with the previously made statements, i.e., heating energy price and total heat consumption will influence possible profit of each technology. District heating market price and electricity market price will have impact on the type of sources which should be operated. The proposed approach is to cover heat demand and use the best energy source combination according to a real day situation in district heating consumption and electricity market to maximise overall profit of all participants.

Mixed integer linear programming can be used to maximise objective function (4) with corresponding constraints, which are represented by inequalities. In the proposed approach, constraints cover fulfilment of heating energy demand, maximum and minimum load of each energy source, CCGT cogeneration heating energy production (operation in a condensing mode or cogeneration), as well as the state of each energy source (operating/ not operating). If some additional profit is made, it should 
be divided among coalition players consid- done using the Shapley value (5) [29]. ering their input into total result, which is

$$
\begin{gathered}
E=\sum_{t=1}^{T}\left(P_{\text {el.gas.t }}\left(C_{\text {el.t. }}-\frac{C_{\text {g.t }}}{\eta_{\text {el.gas }}}\right)+P_{\text {th.gas.t }} C_{\text {th.t }}+P_{\text {th.HOB.t }}\left(C_{\text {th.t }}-\frac{C_{g . t}}{\eta_{H O B}}\right)\right. \\
\left.+P_{\text {el.bio.t }}\left(C_{\text {el.t. }}+\frac{C_{\text {th.t }} \eta_{\text {th.bio }}}{\eta_{\text {el.bio }}}-\frac{C_{\text {bio.t }}}{\eta_{\text {el.bio }}}\right)\right) \rightarrow \text { max } \\
\left\{\begin{array}{c}
P_{\text {th.gas }}+P_{\text {th.HOB }}+\frac{P_{\text {el.bio }} \eta_{\text {th.bio }}}{\eta_{\text {el.bio }}}=P_{\text {th.dem }} \\
P_{\text {el.gas }}-s_{\text {gas }} P_{\text {el.gas.min }} \geq 0 \\
P_{\text {el.gas }}-s_{\text {gas }} P_{\text {el.gas.max }} \leq 0 \\
P_{\text {el.bio }}-s_{\text {bio }} P_{\text {el.bio.min }} \geq 0 \\
P_{\text {el.bio }}-s_{\text {bio }} P_{\text {el.bio.max }} \leq 0 \\
P_{\text {th.HOB }}-s_{\text {HOB }} P_{\text {th.HOB.min }} \geq 0 \\
P_{\text {th.HOB }}-s_{\text {HOB }} P_{\text {th.HOB.max }} \leq 0 \\
P_{\text {el.gas }} \frac{P_{\text {th.gas.max }}}{P_{\text {el.gas.max }}-P_{\text {th.gas }} \geq 0} \\
s_{\text {gas }} \in\{0,1\} \\
s_{\text {bio }} \in\{0,1\} \\
s_{\text {HOB }} \in\{0,1\}
\end{array}\right.
\end{gathered}
$$

where

$P_{\text {el.gasmin }}-$ minimum electrical power of CCGT, MW; $P_{\text {el.gasmax }}-$ maximum electrical power of CCGT, MW; $P_{\text {th.Нов.min }}-$ minimum thermal power of gas fired HOB, MW; $P_{\text {th.HОВ.max }}-$ maximum thermal power of gas fired $\mathrm{HOB}, \mathrm{MW} ; P_{\text {el.biomin }}-$ minimum electrical power of wood chip CHP, MW; $P_{\text {el.bio.max }}-$ maximum electrical power of wood chip CHP, MW; $P_{\text {th.dem }}-$ total heating energy demand during hour $t, \mathrm{MWh} ; s$ - the coefficient that indicates CCGT, HOB and bio fired CHP operation state, i.e., 1 is in operation, 0 is shutdown.

Decision variables are $\mathrm{P}_{\text {el.gas. }}, \mathrm{P}_{\text {th. gas. }}, \mathrm{P}_{\text {th. }}$ нов.. and $\mathrm{P}_{\text {el.bio.t }}$. Additional profit is distributed among coalition players considering

$\Phi_{i}(v, N)=\sum_{S \subset N} \frac{(s-1) !(n-s) !}{n !}[v(S)-v(S-i)]$, their input into total result, which is done using the Shapley value:

where

$v$ - game; $\mathrm{N}$ - any finite carrier of $v$, with $|\mathrm{N}|=\mathrm{n} ; \mathrm{s}$ - coalition; $\mathrm{S}$ - coalitions; $\mathrm{i}$ - the number of players.

The proposed approach could be described in four steps:

1. Calculation of heating energy prices for day/weak-ahead market using Eqs.
(1) and (2), load distribution among sources, considering the heating energy price for the period and electricity market price; 
2. Calculation of profit made by each source from heating energy and electricity trading;

3. Heating load re-dispatch according to objective function (4) as well as recalculation of profit made from heating energy trading, also overall profit and electricity trading profit are calculated;

4. In case if any additional profit is made, the Shapley value is used to split the reward among players according to their contribution and input to the coalition.

\section{CASE STUDY}

For the case study, the district heating area of Riga city in the right bank was chosen as a heating energy consumer. The case study is based on historical data for two different years with the historically lowest electricity market price (34.67 EUR/MWh) and year with the historically highest electricity market price (49.89 EUR/MWh). Heat demand was calculated in accordance with data provided in [27] and using real historical hourly ambient temperature data from the mentioned years. Electricity hourly market prices were taken from NordPool spot market data. Natural gas prices were taken from Gaspool data. Wood chip prices were observed from different sources and prices per MWh were calculated using [30]. It is assumed that the cheapest heating energy source for the studied period of day or week sets its price as 0.97 of the second cheapest heating energy source for a particular period.

Table 1. Technical Parameters of Energy Sources

\begin{tabular}{|c|c|c|c|}
\hline & CCGT & HOB & $\mathrm{BIO} \mathrm{CHP}$ \\
\hline Maximum electrical power, MW & 534 & - & 80 \\
\hline Electrical efficiency, p.u. & 0.42 & - & 0.22 \\
\hline Maximum thermal power, MW & 394 & 464 & 228 \\
\hline Thermal efficiency, p.u. & - & 0.91 & 0.63 \\
\hline Minimum electrical power, MW & 160.2 & - & 48 \\
\hline Minimum thermal power, MW & 0 & 23.2 & 136.8 \\
\hline
\end{tabular}

Technical parameters of energy sources under consideration are provided in Table 1. These data are based on information from [11] and [24], power ratings of facilities were chosen close to existing capacities of thermal power supply in the district heating area of Riga city in the right bank. As the main aim is to study the possibility of dispatch optimization, data do not represent a real situation in the chosen city [2]. Historically, HOBs in Riga are part of CCGT power plants; therefore, in this study CCGT and $\mathrm{HOB}$ are considered to be one player for the Shapley value calculation, the second player is wood chip CHP, which is called BIO CHP in study.

Results of performed calculations before and after optimization for years with different electricity prices are provided in Tables 2 and 3 . In this case, heating energy prices were projected for the day-ahead market. Results show that for the year with the lowest average yearly electricity market price, CCGT heat production hours increased by 
$1.45 \%$, but for the year with the highest average yearly electricity market price there is seen a reduction by $1.09 \%$.

For both years under consideration, HOB operating hours and produced heat energy were decreasing; a decrease in operation hours for the year with the lowest average yearly electricity market price was $10.07 \%$, whereas a decrease in the produced heating energy was $4.63 \%$. For the year with the highest average yearly electricity market price, a decrease in HOB operation hours was $23.49 \%$ and a decrease in production was $15.96 \%$.

The results also show that BIO CHP operating hours and produced heat energy increased; an increase in operation hours for the year with the lowest average yearly electricity market price was $7.38 \%$, and an increase in the produced heat energy was $4.4 \%$. For the year with the highest average yearly electricity market price, an increase in BIO CHP operation hours was $19.83 \%$, and an increase in production was $16.19 \%$.

Numerical results clearly show that the objective function re-dispatches heat generation from CCGT and HOB to a more efficient heating energy production sourceBIO CHP. For both studied years, the most significant reduction of operating hours and produced heating energy was for $\mathrm{HOB}$, especially it was important for the year with high average yearly electricity prices, which allowed producing more electricity using cogeneration power plants and gaining higher profit.

For both studied years, CCGT suffered loss in profit for electricity and heating energy trading. Thus, it allowed increasing profit from electricity and heating energy trading for BIO CHP and reducing losses due to HOB operation. Such a situation after optimization granted additional 443 305 EUR profit for the coalition in the year with a low average yearly electricity price and 1402593 EUR profit in the year with a high average yearly electricity price for the scenario with day-ahead heating energy prices.

Table 2. Results for the Year with the Lowest Average

Yearly Electricity Price and Heating Energy Daily Price Scenario

\begin{tabular}{|l|c|c|c|}
\hline & Before optimization & After optimization & Deviation, $\%$ \\
\hline CCGT heat production hours, h & 4472 & 4537 & 1.45 \\
\hline HOB operating hours, h & 4230 & 3804 & -10.07 \\
\hline BIO CHP operating hours, h & 5067 & 5441 & -2.91 \\
\hline Heat produced by CCGT, MWh & 844541 & 819964 & -4.63 \\
\hline Heat produced by HOB, MWh & 533829 & 509096 & 4.40 \\
\hline Heat produced by BIO CHP, MWh & 1119448 & 1168757 & -0.60 \\
\hline CCGT profit for heating energy, EUR & 8271941 & 8222098 & -20.43 \\
\hline CCGT profit for electricity, EUR & 543077 & 432111 & -10.85 \\
\hline HOB profit for heating energy, EUR & -2772024 & -2471176 & 1.56 \\
\hline BIO CHP profit for heating energy, EUR & 16927557 & 17191366 & -0.36 \\
\hline BIO CHP profit for electricity, EUR & -10895118 & -10855661 & 2.30 \\
\hline Profit for heating energy, EUR & 22427474 & 22492288 & 3.67 \\
\hline Overall profit, EUR & 12075433 & 12518738 & \\
\hline
\end{tabular}


Table 3. Results for the Year with the Highest Average

Yearly Electricity Price and Heating Energy Daily Price Scenario

\begin{tabular}{|l|c|c|c|}
\hline & $\begin{array}{c}\text { Before } \\
\text { optimization }\end{array}$ & After optimization & Deviation, $\%$ \\
\hline CCGT heat production hours, h & 6792 & 6718 & -1.09 \\
\hline HOB operating hours, h & 2537 & 1941 & -23.49 \\
\hline BIO CHP operating hours, h & 4166 & 4992 & 19.83 \\
\hline Heat produced by CCGT, MWh & 1288275 & 1183850 & -8.11 \\
\hline Heat produced by HOB, MWh & 268927 & 226008 & -15.96 \\
\hline Heat produced by BIO CHP, MWh & 910059 & 1057402 & 16.19 \\
\hline CCGT profit for heating energy, EUR & 9123715 & 8606193 & -5.67 \\
\hline CCGT profit for electricity, EUR & 10144276 & 10110785 & -0.33 \\
\hline HOB profit for heating energy, EUR & -3133564 & -2390136 & -23.72 \\
\hline BIO CHP profit for heating energy, EUR & 10272247 & 11037708 & 7.45 \\
\hline BIO CHP profit for electricity, EUR & -4777407 & -4332690 & -9.31 \\
\hline Profit for heating energy, EUR & 16262398 & 17253765 & 6.10 \\
\hline Overall profit, EUR & 21629267 & 23031860 & 6.48 \\
\hline
\end{tabular}

Results for week-ahead projected heating energy prices are presented in Tables 4 and 5 . The results showed similar tendencies with those demonstrated in Tables 2 and 3. Thus, more significant changes appear in profit for heating energy showing a higher decrease of profit for CCGT, lower decrease of losses for $\mathrm{HOB}$ and higher rise in profit for BIO CHP. As a result, the coalition made additional 461428 EUR profit in the year with the lowest average yearly electricity market price and 1445438 EUR profit in the year with the highest average yearly electricity market price, which could be comparable to the day-ahead market scenario and was not enough to compensate overall lower profit. Week-ahead heating energy prices lead to loss of revenue for energy sources due to uncertainties for such a long time span.

Table 4. Results for the Year with the Lowest Average

Yearly Electricity Price and Heating Energy Weekly Price Scenario

\begin{tabular}{|l|c|c|c|}
\hline & $\begin{array}{c}\text { Before } \\
\text { optimization }\end{array}$ & After optimization & Deviation, \% \\
\hline CCGT heat production hours, $h$ & 4472 & 4537 & 1.45 \\
\hline HOB operating hours, h & 4182 & 3756 & -10.19 \\
\hline BIO CHP operating hours, h & 5019 & 5393 & 7.45 \\
\hline Heat produced by CCGT, MWh & 850453 & 819964 & -3.59 \\
\hline Heat produced by HOB, MWh & 522917 & 498100 & -4.75 \\
\hline Heat produced by BIO CHP, MWh & 1105751 & 1157813 & 4.71 \\
\hline CCGT profit for heating energy, EUR & 8785257 & 8588098 & -2.24 \\
\hline CCGT profit for electricity, EUR & 543077 & 432111 & -20.43 \\
\hline HOB profit for heating energy, EUR & -3616430 & -3397972 & -6.04 \\
\hline BIO CHP profit for heating energy, EUR & 15514965 & 16026603 & 3.30 \\
\hline BIO CHP profit for electricity, EUR & -10773503 & -10734046 & -0.37 \\
\hline Profit for heating energy, EUR & 20683792 & 21216729 & 2.58 \\
\hline Overall profit, EUR & 10453366 & 10914794 & 4.41 \\
\hline
\end{tabular}


Table 5. Results for the Year with the Highest Average

Yearly Electricity Price and Heating Energy Weekly Price Scenario

\begin{tabular}{|l|c|c|c|}
\hline & $\begin{array}{c}\text { Before } \\
\text { optimization }\end{array}$ & After optimization & Deviation, \% \\
\hline CCGT heat production hours, $h$ & 6745 & 6671 & -1.10 \\
\hline HOB operating hours, $h$ & 2537 & 1940 & -23.53 \\
\hline BIO CHP operating hours, $\mathrm{h}$ & 4118 & 4944 & 20.06 \\
\hline Heat produced by CCGT, MWh & 1278086 & 1173661 & -8.17 \\
\hline Heat produced by HOB, MWh & 273717 & 225773 & -17.52 \\
\hline Heat produced by BIO CHP, MWh & 897517 & 1046458 & 16.59 \\
\hline CCGT profit for heating energy, EUR & 9038790 & 7923570 & -12.34 \\
\hline CCGT profit for electricity, EUR & 10304741 & 10271250 & -0.33 \\
\hline HOB profit for heating energy, EUR & -3843747 & -3116027 & -18.93 \\
\hline BIO CHP profit for heating energy, EUR & 8831410 & 10253123 & 16.10 \\
\hline BIO CHP profit for electricity, EUR & -4743137 & -4298421 & -9.38 \\
\hline Profit for heating energy, EUR & 14026453 & 15060666 & 7.37 \\
\hline Overall profit, EUR & 19588057 & 21033495 & 7.38 \\
\hline
\end{tabular}

Graphical results of optimisation are presented in Figs. 1 and 2 for the same day of the year with the highest average yearly electricity market price. During first 7 hours and last 3 hours of the day, electricity prices were below $63 \mathrm{EUR} / \mathrm{MWh}$, the prices during the remaining hours of the day were higher. Heat demand was stable almost all day long. Before optimization, CCGT raised both electrical and thermal power to maximum when electricity price increased. Due to heating energy balance, this led to a decrease in heating power of BIO CHP, which also resulted in reduction of electricity production because of inabil- ity to operate in a condensing mode. After optimization, CCGT kept heating energy all day long below $332 \mathrm{MW}$ to allow BIO $\mathrm{CHP}$ to operate at its maximum, granting as much as possible electrical energy to raise overall income of the coalition due to very high electricity prices. Before optimization, heating load was covered by the source with the lowest heating energy costs calculated by Eq. (1). After optimization, little loss in income for heating energy was made to gain higher profit during hours with high electricity prices, which led to overall greater income.

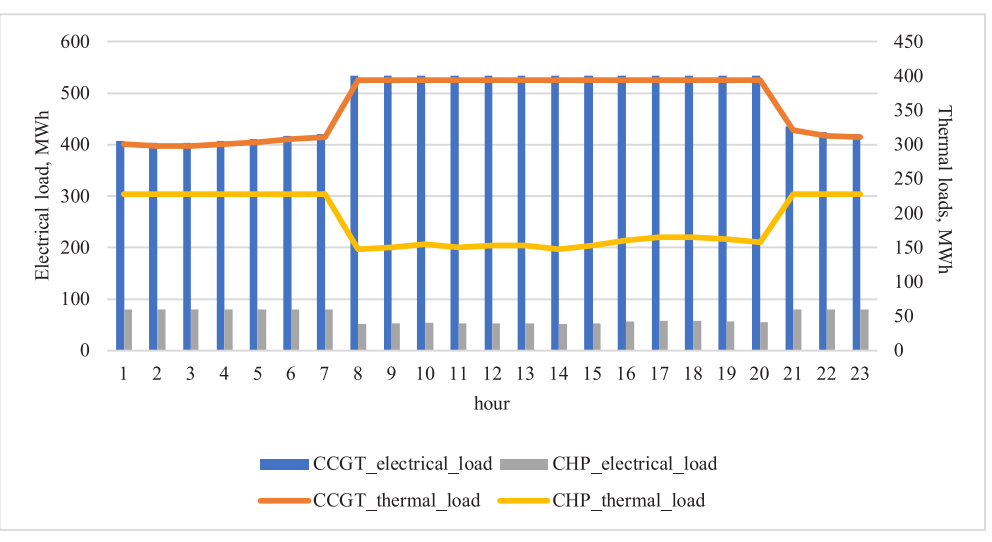

Fig. 1. Dispatch of electrical and heating load, 18 December 2018. 


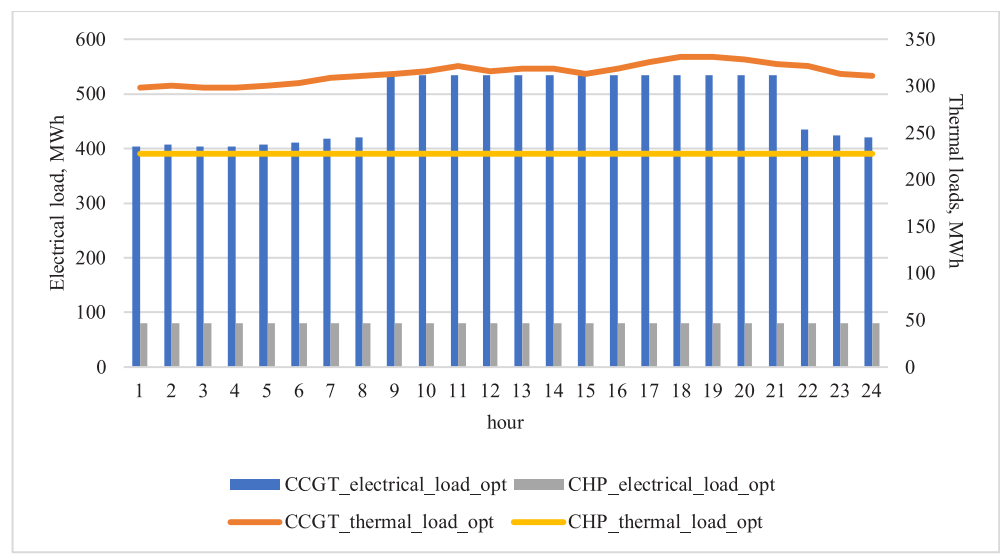

Fig. 2. Dispatch of electrical and heating load after optimization, 18 December 2018.

For both years and heating energy market scenarios, growth in profit was achieved; this additional profit was divided according to the Shapley value between energy sources that formed the coalition. In this case study, CCGT and HOB are considered to be one player. The second player is wood chip CHP. Results of profit split by the Shapley value are presented in Tables 6 and 7; only data for the day-ahead heating energy market are presented. As there are only two players, all additional profit is divided between parties, granting equal additional income. Comparing the results of Tables 2 and 3 to those of Tables 6 and 7, it becomes obvious that the use of the Shapley value is necessary to make players interested in participation in the coalition. Table 3 shows that an overall increase in profit of CCGT and HOB is only 192415 EUR, but after the use of the Shapley value (Table 7), an increase is 701296.5 EUR.

Table 6. Shapley Value of the Case Study for Heating Energy Day-Ahead Market in the Year with the Lowest Average Yearly Electricity Price

\begin{tabular}{|l|l|l|}
\hline & CCGT+HOB & BIO CHP \\
\hline Profit before optimization, EUR & 6042994 & 6032439 \\
\hline Profit after optimization, EUR & 6183033 & 6335705 \\
\hline Shapley value, EUR & 6264646.5 & 6254091.5 \\
\hline Increase in profit for heating energy, EUR & 221652.5 & 221652.5 \\
\hline
\end{tabular}

Table 7. Shapley Value of the Case Study for Heating Energy Day-Ahead Market in the Year with the Highest Average Yearly Electricity Price

\begin{tabular}{|l|l|l|}
\hline & CCGT+HOB & BIO CHP \\
\hline Profit for heating energy before optimization, EUR & 16134427 & 5494840 \\
\hline Profit for heating energy after optimization, EUR & 16326842 & 6705018 \\
\hline Shapley value, EUR & 16835723.5 & 6196136.5 \\
\hline Increase in profit for heating energy, EUR & 701296.5 & 701296.5 \\
\hline
\end{tabular}

The case study indicated a problem with the number of start-ups, which was essential in case of CCGT and CHP power plants because of significant costs of start- ups for both gas fired and wood chip fired CHPs [31], [32]. Numerous star-ups can also lead to technical problems of the main equipment [33]. For example, in case of the 
year with the lowest average yearly electricity market price and day-ahead heating energy market, there were 410 CCGT startups before optimization, but after optimization -426 . Both numbers indicate almost 10 times higher than the usual number of start-ups for Latvian CCGTs. For BIO CHP, the number of start-ups before optimization was 246 and after optimization -215 , which showed a $12.6 \%$ decrease, but still it was a very high number of start-ups. To avoid such a significant number of startups, objective function (4) should be modified by adding additional costs for start-ups of energy sources, also start-up time should be considered. This additional constraints should be considered in calculations before optimization.

\section{CONCLUSIONS}

The developed methodology and proposed optimization objective function were tested on historical hourly data and proved to be efficient for dispatching different heating energy and electricity sources in order to gain higher overall profit from the formed coalition, considering participation in both electricity and district heating markets and ensuring heat energy delivery corresponding to the demand. The use of the Shapley value allows rewarding players according to their input in the total coalition profit, thus granting an increase in profit to all involved parties.

The Shapley value allowed splitting additional profit between coalition parties after optimization in such a way that all involved parties increased their profit from electricity and heating energy trading. This additional profit could be used to partly compensate heating energy tariffs for district heating users.

Comparison of two heating energy market price formation models shows that the day-ahead heating energy market can grant higher overall profit to market participants than the week-ahead market price. It could be explained by higher uncertainties for longer time span, but it was not under the scope of this study. Optimization results show an identical increase in profit for both day-ahead and week-ahead markets. In case of the week-ahead market, additional profit is not enough to compensate loses in profit comparing to a scenario with the day-ahead heating energy prices.

Both initial data and optimized data indicate hundreds of start-ups per year for the studied technologies, which in reality are impossible for BIO CHPs and quite harmful for CCGTs. This should be considered in the next study.

To solve objective function (4), a special program solving MILP was developed, and data for optimization could be uploaded in Microsoft Excel format. Total calculation time and generation of resulting file take under 1 minute for one year calculations for three different energy sources. The use of such a program could be very handful because it is based on common computing programs.

\section{FURTHER RESEARCH}

The proposed optimization objective function should be extended and include start-up costs and time of technologies as well as costs of $\mathrm{CO}_{2}$ emission footprint. It 
should also be extended by means of heat-

ing energy and electrical energy storage, as well as electrical HOBs.

\section{ACKNOWLEDGEMENTS}

The research has been supported by the Ministry of Economics of the Republic of Latvia, project "Future-Proof Development of the Latvian power system in an Integrated Europe (FutureProof)", project
No. VPP-EM-INFRA-2018/1-0005 and by the Latvian Council of Science, project "Management and Operation of an Intelligent Power System (I-POWER)" (No. lzp2018/1-0066).

\section{REFERENCES}

1. Fleiter, T., Steinbach, J., \& Ragwitz, M. (2016). Mapping and Analyses of the Current and Future (2020-2030) Heating/Cooling Fuel Deployment (Fossil/Renewables). European Commission DirectorateGeneral for Energy. Available at https:// ec.europa.eu/energy/studies/mapping-andanalyses-current-and-future-2020-2030heatingcooling-fuel-deployment_en

2. Deshko, V. I., Zamulko, A. I., Karpenko, D. S., Mahnitko, A., \& Linkevics, O. (2018). Evaluation of the district heating market efficiency as the function of its size and number of competing suppliers. In 2018 IEEE 59th Annual International Scientific Conference on Power and Electrical Engineering of Riga Technical University, RTUCON 2018 (pp. 1-7), 12-14 November 2018, Riga, Latvia. doi:10.1109/ RTUCON.2018.8659907.

3. Dorfner, J., \& Hamacher, T. (2014). Large-Scale District Heating Network Optimization. IEEE Transactions on Smart Grid, 5 (4), 1884-1891. doi:10.1109/ TSG.2013.2295856

4. Ivanova, P., Sauhats, A., Linkevics, O., \& Balodis, M. (2016). Combined heat and power plants towards efficient and flexible operation. In EEEIC 2016 - International Conference on Environment and Electrical Engineering (2434-2439), 7-10 June 2016, Florence, Italy. doi:10.1109/ EEEIC.2016.7555874.
5. Rezaie, B., \& Rosen, M. A. (2012). District Heating and Cooling: Review of Technology and Potential Enhancements. Applied Energy, 93, 2-10. doi:10.1016/j. apenergy.2011.04.020.

6. EuroHeat \& Power. (2013). District Heating and Cooling. Country by Country Survey 2013. Available at http://www.euroheat.org/ Publications/

7. Hemmes, K., Zachariah-Wolf, J. L., Geidl, M., \&Andersson, G. (2007). Towards MultiSource Multi-Product Energy Systems. International Journal of Hydrogen Energy, 32 (10-11), 1332-1338. doi:10.1016/j. ijhydene.2006.10.013.

8. Shabanpour-Haghighi, A., \& Seifi, A. R. (2016). An Integrated Steady-State Operation Assessment of Electrical, Natural Gas, and District Heating Networks. IEEE Transactions on Power Systems, 31 (5), 3636-3647. doi:10.1109/ TPWRS.2015.2486819.

9. Rolfsman, B. (2004). Combined Heatand-Power Plants and District Heating in a Deregulated Electricity Market. Applied Energy, 78 (1), 37-52. doi:10.1016/S03062619(03)00098-9.

10. Mathiesen, B. V., \& Lund, H. (2009). Comparative Analyses of Seven Technologies to Facilitate the Integration of Fluctuating Renewable Energy Sources. IET Renewable Power Generation, 3 (2), 190-204. doi:10.1049/iet-rpg:20080049. 
11. Bioenergy Europe. (n.d.). Statistical Report. Available at https://bioenergyeurope.org/ statistical-report.html

12. Uris, M., Linares, J. I., \& Arenas, E. (2015). Size Optimization of a Biomass-Fired Cogeneration Plant CHP/CCHP (Combined Heat and Power/Combined Heat, Cooling and Power) Based on Organic Rankine Cycle for a District Network in Spain. Energy, 88, 935-945. doi:10.1016/j. energy.2015.07.054.

13. Schneider, T., Müller, D., \& Karl, J. (2020). A Review of Thermochemical Biomass Conversion Combined with Stirling Engines for the Small-Scale Cogeneration of Heat and Power. Renewable and Sustainable Energy Reviews, 134. doi:10.1016/j.rser. 2020.110288.

14. Liu, X., Wu, J., Jenkins, N., \& Bagdanavicius, A. (2016). Combined Analysis of Electricity and Heat Networks. Applied Energy, 162, 1238-1250. doi:10.1016/j.apenergy.2015.01.102.

15. Wang, J., You, S., Zong, Y., Traeholt, C., Zhou, Y., \& Mu, S. (2019). Optimal Dispatch of Combined Heat and Power Plant in Integrated Energy System: A State of the Art Review and Case Study of Copenhagen. Energy Procedia, 158, 2794 2799. doi:10.1016/j.egypro.2019.02.040.

16. Geidl, M., \& Andersson, G. (2007). Optimal Power Flow of Multiple Energy Carriers. IEEE Transactions on Power Systems, 22 (1), 145-155. doi:10.1109/ TPWRS.2006.888988.

17. Fanti, M. P., Mangini, A. M., Roccotelli, M., \& Ukovich, W. (2015). A District Energy Management Based on Thermal Comfort Satisfaction and Real-Time Power Balancing. IEEE Transactions on Automation Science and Engineering, 12 (4), 1271-1284. doi:10.1109/TASE.2015.2472956.

18. Borcsok, E., Gersc, A., \& Fulop, J. (2018). Applying Multiobjective Optimization for the Heat Supply in the Residential Sector in Budapest. In SACI 2018 IEEE 12th International Symposium on Applied Computational Intelligence and Informatics, (pp. 213-217), 17-19 May 2018, Timisoara, Romania. doi:10.1109/
SACI.2018.8440986.

19. Siewierski, T., Pajak, T., \& Delag, M. (2018). Optimisation of cogeneration units in large heating systems. In International Conference on Software, Knowledge Information, Industrial Management and Applications, SKIMA (pp. 1-7), 6-8 December 2017, Colombo, Sri Lanka. doi:10.1109/SKIMA.2017.8294129.

20. Chen, Y., Xu, Y., Li, Z., Feng, S., Hu, C., \& Hai, K. L. (2019). Optimally coordinated operation of a multi-energy microgrid with coupled electrical and heat networks. In 2018 International Conference on Power System Technology, POWERCON 2018, (pp. 218-224), 6-8 November 2018, Guangzhou, China. doi:10.1109/ POWERCON.2018.8602048.

21. Zhou, H., Li, Z., Zheng, J. H., Wu, Q. H., \& Zhang, H. (2020). Robust Scheduling of Integrated Electricity and Heating System Hedging Heating Network Uncertainties. IEEE Transactions on Smart Grid, 11 (2), 1543-1555. doi:10.1109/ TSG.2019.2940031.

22. Reynolds, J., Ahmad, M. W., \& Rezgui, Y. (2018). District heating energy generation optimisation considering thermal storage. In 2018 6th IEEE International Conference on Smart Energy Grid Engineering, SEGE 2018, (pp. 330-335), 11-13 August 2018, Ontario, Canada. doi:10.1109/ SEGE.2018.8499509.

23. Moshkin, I., \& Sauhats, A. (2016). Solving district heating problems by using cooperative game theory methods. In EEEIC 2016 - International Conference on Environment and Electrical Engineering, (pp. 1-5), 6-9 June 2017, Florence, Italy. doi:10.1109/EEEIC.2016.7555462.

24. Simons G., \& Barsun, S. (2017). Combined Heat and Power Evaluation Protocol. Davis, California. Available at https://www. nrel.gov/docs/fy17osti/68579.pdf

25. Muche, T., Höge, C., Renner, O., \& Pohl, R. (2016). Profitability of Participation in Control Reserve Market for BiomassFueled Combined Heat and Power Plants. Renewable Energy, 90, 62-76. doi:10.1016/j.renene.2015.12.051. 
26. Lako, P., Koyama, M., \& Nakada, S. (2015). Biomass for Heat and Power. Technology Brief, IEA-ETSAP and IRENA Technology Brief E05. Available at https://irena.org/-/ media/Files/IRENA/Agency/Publication/ 2015/IRENA-ETSAP_Tech_Brief_E05 Biomass-for-Heat-and-Power.pdf

27. Broka, Z., Kozadajevs, J., Sauhats, A., Finn, D. P., \& Turner, W. J. N. (2016). Modelling residential heat demand supplied by a local smart electric thermal storage system. In 57th International Scientific Conference on Power and Electrical Engineering of Riga Technical University, RTUCON 2016, 13-14 October 2016, Riga \& Cesis, Latvia. doi:10.1109/RTUCON.2016.7763128 .

28. Sauhats, A., Kozadajevs, J., Dolgicers, A., Zalitis, I., \& Boreiko, D. (2019). The impact of the district heating system thermal inertia on the CHPP operation mode. In 2019 IEEE 60th Annual International Scientific Conference on Power and Electrical Engineering of Riga Technical University, RTUCON 2019, 7-9 October 2019, Riga, Latvia. doi:10.1109/ RTUCON48111.2019.8982254.

29. Lloyd S., \& Shapley A., (1951). Value for n-person games. In H.W. Kuhn and A.W. Tucker (eds.), Contributions to the Theory of Games (vol. II). Annals of Mathematical Studies (v. 28), pp. 307-317. Princeton: Princeton University Press.
30. TechLine (n.d.) Fuel Value Calculator. Available at https://www.fpl.fs.fed.us/ documnts/techline/fuel-value-calculator. pdf

31. Ivanova, P., Linkevics, O., \& Sauhats, A. (2017). Mathematical description of combined cycle gas turbine power plants' transient modes. In 17th IEEE International Conference on Environment and Electrical Engineering and 1st IEEE Industrial and Commercial Power Systems Europe, EEEIC / I and CPS Europe 2017, (pp. 61-66), 6-9 June 2017, Milan, Italy. doi:10.1109/ EEEIC.2017.7977405

32. Kumar, A., Cameron, J. B., \& Flynn, P. C. (2003). Biomass Power Cost and Optimum Plant Size in Western Canada. Biomass and Bioenergy, 24 (6), 445-464. doi:10.1016/ S0961-9534(02)00149-6.

33. Oleksijs, R., \& Olekshii, B. (2019). Combined heat and power plant electrical equipment incident rate and unavailability empirical expression. In the Advances in Information, Electronic and Electrical Engineering, AIEEE 2019 - Proceedings of the 7th IEEE Workshop, 15-16 November 2018, Liepaja, Latvia. doi:10.1109/ AIEEE48629.2019.8976989. 